\title{
Hepatic Artery Embolization
}

National Cancer Institute

\section{Source}

National Cancer Institute. Hepatic Artery Embolization. NCI Thesaurus. Code C66902.

A therapeutic procedure involving the injection or deployment of blocking agents in the hepatic artery to treat tumors. 